\title{
Facilities and Equipment as Predictors of Effective Health Care Delivery Services in Selected State Government Hospitals in Oyo State, Nigeria
}

\author{
B. O. Ogundele and H.O. Olafimihan \\ Department of Human Kinetics and Health Education, Faculty of Education, \\ University of Ibadan, Ibadan, Nigeria
}

\begin{abstract}
KEYWORDS Adequacy. Availability. Diagnostic Facilities. Hi-Technology Equipment. Physical Facilities. Provision
\end{abstract}
\begin{abstract}
This study seek to examine the impact of facilities and equipment as predicting effective health care delivery in selected state government hospitals in Oyo State. Four hypothese were formulated and tested at 0.05 alpha level. A total of 1,220 respondents were randomly selected for the study. The instruments for the study were a structured questionnaire on facilities and equipment as predictors of effective health care delivery service and checklist of items on Infrastructure and equipment. The results from the study indicated that facilities, Equipment and Adequacy of facilities and Equipment were statistically significant and predict effective health care delivery service while Availability of facilities and equipment was found not to be significant and could not predict effective health care delivery services. The implication from this finding shows that facilities, equipment and adequacy of facilities and equipment actually predicted effective health care delivery service while availability of facilities and equipment did not predict effective health care delivery services.
\end{abstract}

\section{INTRODUCTION}

Over the years, the issue of facilities and equipment has been a major source of concern among health practitioners and various stakeholders in the health care delivery system. The infrastructure in health are the physical facilities at primary, secondary and tertiary levels of the health care delivery. These facilities may be classified into those managed by government i.e. the public sector facilities and those that are privately owned by single individuals, group practitioners, voluntary and industrial organizations (Erinosho 1996).

Infrastructure maintenance and new construction according to Omotosho (2002) was mostly ignored for about 10 years prior to 1998 . He observed that since then, the government has been upgrading some facilities. However, medical facility capabilities will noticeably improve in the near future if funding continues.

In the area of medical material, it was observed that Nigeria imports 80 percent of its pharmaceutical and medical supply needs, primarily from European sources. Domestic medical and pharmaceutical manufacturing plants currently are operating at approximately 40 percent capacity (Omotosho 2002). Thus, medical material shortages have hindered medical practice, research and training and that blood supply is not safe and that blood banking services are unacceptable by United States standards.

Encyclopedia Britannica (2002) reiterated the need for adequate and efficient facilities and equipment based on the premise that hospitals concentrate on caring for the acutely sick and injured persons and on outpatient services. It was equally reported that a modern general hospital, even of moderate size, is a complex institution and apart from its purely medical functions, it must also provide shelter, heat, food and other services to its patients and staff.

As part of provision of facilities, a substantial area of a hospital building is given to boiler rooms and store rooms, laundries, kitchens, cafeterias and linen rooms. The medical services require space for laboratories, $\mathrm{x}$-ray and other diagnostic equipment, a pharmacy, an emergency room, operating rooms, delivery rooms for obstetric cases, a pathology laboratory, nurse's stations, a morgue and accommodations for various types of treatment such as physical and occupational therapy. Patients' accommodation include wards, semiprivate (two to six beds) and private rooms, isolation rooms, nurseries, special nurseries for premature babies, lounges and waiting rooms. In addition, the hospital administration must have offices for accounting and record keeping. Facilities for schools of nursing that require a variety of dormitory, classroom and laboratory 
accommodation for students are required. (Wagnall's Encyclopedia 2002).

Thus, for ensuring functional health care delivery system in Oyo State hospitals, there is the need for provision of facilities and equipment as well as their availability and adequacy.

\section{Research Hypotheses}

The following null hypothesis were generated and tested for the study.

1. The provision of facilities will not significantly predict effective health care delivery in selected state government hospitals in Oyo State, Nigeria.

2. The provision of equipment will not significantly predict effective health care delivery in selected state government hospitals in Oyo State Nigeria.

3. Availability of facilities and equipment will not significantly predict effective health care delivery services in selected state government hospitals in Oyo State, Nigeria.

4. Adequacy of facilities and equipment will not significantly predict effective health care delivery services in selected state government hospitals in Oyo State, Nigeria.

\section{MATERIAL AND METHODS}

Research Design: The descriptive survey research design was used for this study. The design was chosen simply because it entails investigation in which self report data were collected from samples with the purpose of describing population on some variable of interest (Osuala 1993; Best 1986; Awosika 1992).

Population: The population for this study was made up of Doctors, Nurses/Nurse midwife, pharmacist, Laboratory Technologist and other health care providers such as hospital secretaries, Radiographers, the administrative staff and ward aids that constituted the subject from the zonal health care facility in Oyo State.

Sample and Sampling Technique: A total of one thousand, two hundred and twenty (1220) i.e. $81 \%$ out of the initial projection of one thousand five hundred (1500) health care providers using purposive and convenient sampling techniques form the samples for the study. They were drawn from the five (5) zones comprising two randomly selected health care facility from each zonal health boards using multi- stage sampling technique to select the hospitals in Oyo State.

Instrument: The instrument used for this study comprised of a self-developed questionnaires based on a modified four likert point scale of Strongly Agree (SA) Agree (A) Disagree (D) and Strongly Disagree (SD) on facilities and equipment and a checklist of items indicating the availability and adequacy of facilities and equipment to further elicit more information from the subjects and as well corroborate the observations made.

Data Analysis: The data collected were analysed using multiple regression. Information collected from the checklist of items on availability and adequacy of physical facilities, equipment as well as diagnostic facilities and equipment were subjected to percentages and used under findings and discussion of data collected as additional information made by the respondents in each health care facility used for the study.

The rational behind the use of multiple Regression is the fact that it is a method for studying the effect and the magnitude of the effect of more than one independent variable on the dependent variable, using principles of correlation and regression (Kerlinger and Lee 2000).

The final decision therefore (i.e. failure to reject or rejection) on the hypotheses tested was set at .05 level of significance.

\section{RESULTS AND DISCUSSION}

\section{Demographic Analysis of Respondents}

In table 1 above on sex and age range, it shows that seven hundred and seventy two $(63.3 \%$ were females while four hundred and forty eight $(36.7 \%)$ were males. Also one hundred and thirty two $(10.8 \%)$ were between $50-59$ years, three hundred and seventy two $(30.5 \%)$ were between $40-49$ years, five hundred and four $(41.3 \%)$ falls between $30-39$ years and two hundred and twelve $(17.4 \%)$ were in the range of less than 30 years.

Table 2 shows that three hundred and twelve $(25.6 \%)$ were singles while nine hundred and eight (74.4\%) were married. Looking at the area of specialty, it shows that one hundred and fortytwo $(11.6 \%)$ were medical doctors while seven hundred and ninety two (64.9\%) were nurses/ nurse midwife. Also fifty six (4.6\%) were pharmacists, seventy eight (6.4\%) were laboratory technologists while one hundred and fifty two 
(12.5\%) constitute others i.e. radiographers, physiotherapists, hospital secretaries, accountants, record officers and ward aids.

On work experience of the respondents, table 3 above shows that two hundred and eight $(23.6 \%)$ had $0-4$ years followed by two hundred and forty six $(20.2 \%)$ had $10-14$ years while the least number of respondents forty two (3.5\%) falls between 25-29 years and 30-34 years respectively.

\section{Hypotheses Testing}

Hypothesis I: The first null hypothesis states that provision of facilities will not be a significant predicting factor in effective health care delivery services in selected state government hospitals in Oyo State Nigeria.

The table 4 reveals that the b-value $(-0.135)$ which shows the contribution of facilities on effective health care delivery services. The standardized regression weight (Beta) is $(-0.064)$ which is a reflection of the relationship between facilities and effective health care delivery services. The $t=(-2.251)$ at $\alpha=0.025$ is statistically significant. Since 0.025 is $<.05$ is therefore significant. As a result of this, the null hypothesis which states that provision of facilities will not be a significant predicting factor in effective health care delivery services is therefore not accepted.

In view of the findings and rejection of the null hypothesis, facilities therefore is a strong predicting factor in effective health care delivery services. Though, the findings on facilities as predicting effective health care delivery services supports the submission of Encyclopedia Britannica (2002) that as part of provision of facilities, the medical services require space for laboratories, X-ray and other diagnostic equipment, a pharmacy and emergency rooms, operating rooms, delivery rooms for obstetric cases, a pathology laboratory, nurses stations, morgue and accommodation for various types of treatment such as physical and occupational therapy. It is therefore very important and as well essential for hospital administration to have adequate facilities for those areas highlighted above as well as offices for accounting and record keeping, some could include facilities for schools of nursing that require a variety of dormitory, classroom and laboratory accommodation for students. In view of the above, it is highly essential for hospitals irrespective of status and location to have adequate provision of facilities in discharging its duties effectively and optimally.

Hypothesis 2: The second null hypothesis states that provision of equipment will not be a significant predicting factor in effective health care delivery services in selected state government hospitals in Oyo State, Nigeria.

Table 5 indicates that the b-value of the independent variable (equipment) is $(-0.135)$ which shows the level of contribution of equipment to the prediction of effective health care delivery services. The standardized regression weight (Beta) is (-0.064), which is a reflection of the relationship between equipment and effective

Table 1: Sex and age range of respondents

\begin{tabular}{lcccccc}
\hline & Sex & & \multicolumn{4}{c}{ Age range } \\
\cline { 1 - 2 } \cline { 5 - 7 } Male & Female & & $(50-59)$ & $(40-49)$ & $(30-39)$ & Less Than 30 \\
\hline 448 & 772 & & 132 & 372 & 504 & 212 \\
$36.7 \%$ & $63.3 \%$ & & $10.8 \%$ & $30.5 \%$ & $41.3 \%$ & $17.4 \%$ \\
\hline
\end{tabular}

Table 2: Marital status and area of specialty of respondents

\begin{tabular}{|c|c|c|c|c|c|c|}
\hline \multicolumn{2}{|c|}{ Marital status } & \multicolumn{4}{|c|}{ Specialty } & \multirow[b]{2}{*}{ Others } \\
\hline Single & Married & $\begin{array}{l}\text { Medical } \\
\text { Doctors }\end{array}$ & $\begin{array}{c}\text { Nursel } \\
\text { Midwife }\end{array}$ & Pharm. & Lab. Tech. & \\
\hline 312 & 908 & 142 & 792 & 56 & 78 & 152 \\
\hline $25.6 \%$ & $74.4 \%$ & $11 / 6 \%$ & $64.9 \%$ & $4.6 \%$ & $6.4 \%$ & $12.5 \%$ \\
\hline
\end{tabular}

Table 3: Work experience of respondents

\begin{tabular}{lcccccc}
\hline \multicolumn{5}{c}{ Work experience } \\
\hline$(0-4)$ yrs & $(5-9)$ yrs & $(10-14)$ yrs & $(15-19)$ yrs & (20-24) yrs & (25-29) yrs & $(30-34)$ yrs \\
\hline 288 & 238 & 246 & 188 & 176 & 42 & 42 \\
$23.6 \%$ & $19.4 \%$ & $20.2 \%$ & $15.4 \%$ & $14.4 \%$ & $3.5 \%$ & $3.5 \%$ \\
\hline
\end{tabular}


health care delivery services. The t- $(-2.251)$ at $\alpha$ $=0.025$ is statistically significant. Since 0.025 is $<0.05$, this is therefore significant. Consequently the null hypothesis which states that equipment will not be a significant predicting factor in effective health care delivery services is therefore rejected. Consequent on the findings and rejection of the null hypothesis, equipment is a strong predicting factor in effective health care delivery services.

In view of the fact that the findings on provision of equipment negates the hypothesis stated, Adetunji (2003) examining the importance of equipment in effective health care delivery services in Oyo State, observed that most equipment were obsolete and some outdated, many need repairs and more needed to be replaced. Also Ofi (1998) submitted that inadequate facilities and resources especially basic resources to provide services have created room for substandard care. The lack of basic amenities like water, steam and electricity have hindered the provision of quality health care, conduct of tests, therapies, investigation and surgery. It is obvious from this observations and findings that urgent action is therefore required to improve the state of equipment in various hospitals in Oyo State so as to ensure quality of health care service delivery.

Hypothesis 3: Availability of facilities and equipment will not significantly predict effective health care delivery services in selected state government hospitals in Oyo State, Nigeria.
The table 6 reveals that the b-value $(1.397 \mathrm{E}-$ 02) which shows the contribution of availability of facilities and equipment to the prediction of effective health care delivery services. The standardized regression weight (Beta) is (.041) which reveals the relationship between availability of facilities and equipment and effective health care delivery services. The $\mathrm{t}=(1.447)$ at $\alpha=.148$ is not statistically significant. Since .148 is $>0.05$, this is therefore not significant (NS). Therefore the null hypothesis which states that availability of facilities and equipment will not significantly predict effective health care services is therefore not rejected.

Despite the fact that the hypothesis was accepted in that availability of facilities and equipment is not a significant predicting factor in effective health care delivery services, Encyclopaedia Britannica (2002) still maintained that availability of facilities and equipment in health care services is an area that required maximum and unrelenting attention. It further submitted that the medical services require space for its numerous functions; such as laboratories, $\mathrm{x}$-ray and other diagnostic equipment, a pharmacy and emergency rooms, operating rooms, delivery rooms for obstetric cases and many other functions. Also, availability of functional equipment is indeed very crucial to successful health care delivery services in our hospitals.

Hypothesis 4: Adequacy of facilities and equipment will not significantly predict effective

Table 4: Relative effect of facilities on effective health cares delivery services.

\begin{tabular}{|c|c|c|c|c|c|c|}
\hline \multirow[t]{2}{*}{ Model } & \multicolumn{2}{|c|}{$\begin{array}{c}\text { Un-standardized } \\
\text { co-efficient }\end{array}$} & \multirow{2}{*}{$\begin{array}{c}\begin{array}{c}\text { Standardized } \\
\text { co-efficient }\end{array} \\
\text { Beta }\end{array}$} & \multirow[t]{2}{*}{$t$} & \multirow[t]{2}{*}{ Sig. } & \multirow[t]{2}{*}{ Remark } \\
\hline & $B$ & $\overline{\text { Std Error }}$ & & & & \\
\hline Facilities & -0.135 & 0.060 & -0.064 & -2.25 & 0.025 & Sig. \\
\hline
\end{tabular}

Table 5: Relative effect of equipment on effective health care delivery services.

\begin{tabular}{|c|c|c|c|c|c|c|}
\hline \multirow[t]{2}{*}{ Model } & \multicolumn{2}{|c|}{$\begin{array}{c}\text { Un-standardized } \\
\text { co-efficient }\end{array}$} & \multirow{2}{*}{$\begin{array}{c}\begin{array}{c}\text { Standardized } \\
\text { co-efficient }\end{array} \\
\text { Beta }\end{array}$} & \multirow[t]{2}{*}{$t$} & \multirow[t]{2}{*}{ Sig. } & \multirow[t]{2}{*}{ Remark } \\
\hline & $B$ & Std Error & & & & \\
\hline Equipment & -0.135 & 0.060 & -0.064 & 2.251 & 0.025 & Sig. \\
\hline
\end{tabular}

Table 6: Relative effect of availability of facilities and equipment on effective health care delivery services.

\begin{tabular}{|c|c|c|c|c|c|c|}
\hline \multirow[t]{2}{*}{ Model } & \multicolumn{2}{|c|}{$\begin{array}{c}\text { Un-standardized } \\
\text { co-efficient }\end{array}$} & \multirow{2}{*}{$\begin{array}{c}\begin{array}{c}\text { Standardized } \\
\text { co-efficient }\end{array} \\
\text { Beta }\end{array}$} & \multirow[t]{2}{*}{$t$} & \multirow[t]{2}{*}{ Sig. } & \multirow[t]{2}{*}{ Remark } \\
\hline & $B$ & Std Error & & & & \\
\hline $\begin{array}{l}\text { Availability of facilities } \\
\text { and Equipment }\end{array}$ & $1.397 \mathrm{E}-02$ & .010 & .041 & 1.447 & .148 & \\
\hline
\end{tabular}


health care delivery services in selected state government hospitals in Oyo State, Nigeria.

From the table 7 , it shows that the b-value (2.807E-02) which shows the contribution of adequacy of facilities and equipment on effective health care delivery services. The standardized regression weight (Beta) is (.085), which is a reflection of the relationship between adequacy of facilities and equipment and effective health care delivery services. The $\mathrm{t}=(2.964)$ at $\alpha=.003$ is statistically significant. Since .003 is <.05 is therefore significant. As a result of this, the null hypothesis which states that adequacy of facilities and equipment will not significantly predict effective health care delivery services is therefore not accepted.

Consequent on the findings and rejection of the null hypothesis, adequacy of facilities and equipment is a strong predictor in effective health care services. The findings of the study confirm the statement of Adetunji (2003) on the observations and recommendation of the sub commi- ttee who noted the poor state of infrastructure of health facilities and poor state of equipment in the health facilities, recommended massive renovation of these facilities as well as re-equipping the facilities and setting up an equipment maintenance unit. Essentially, it should be noted from the above findings that equipment and facilities should be adequate to meet with the current changes in the world health care drive and better health for all citizens globally.

From the Table 8, it was observed that most of the items in the checklist under availability showed that they were available except conference room, medical library, assistant director of nursing's office, telephone services, food vendor or canteen unit, mortuary unit and sanitary waste receptacle which had their percentage of non availability of $60.2 \%, 76.9 \%$, $56.2 \%, 57.7 \%, 56.6 \%, 55.1 \%$ and $50.3 \%$ respectively

With respect to the issue of adequacy of the items under physical facilities, it was observed

Table 7: Relative effect of adequacy of facilities and equipment on effective health care delivery services.

\begin{tabular}{|c|c|c|c|c|c|c|}
\hline \multirow[t]{2}{*}{ Model } & \multicolumn{2}{|c|}{$\begin{array}{l}\text { Un-standardized } \\
\text { co-efficient }\end{array}$} & \multirow{2}{*}{$\begin{array}{c}\begin{array}{c}\text { Standardized } \\
\text { co-efficient }\end{array} \\
\text { Beta }\end{array}$} & \multirow[t]{2}{*}{$t$} & \multirow[t]{2}{*}{ Sig. } & \multirow[t]{2}{*}{ Remark } \\
\hline & $B$ & Std Error & & & & \\
\hline $\begin{array}{l}\text { Adequacy of facilities } \\
\text { and Equipment }\end{array}$ & 2.807-E-02 & .009 & .085 & 2.964 & .003 & \\
\hline
\end{tabular}

Table 8: The frequency and percentage of respondents from checklist on availability and adequacy of physical facilities in effective health care delivery services in selected state government hospitals in Oyo State, Nigeria $(\mathrm{N}=1220)$

\begin{tabular}{|c|c|c|c|c|c|}
\hline \multirow{2}{*}{$\begin{array}{l}\text { S. } \\
\text { No. }\end{array}$} & \multirow{2}{*}{$\begin{array}{c}\text { Physical facilities } \\
\text { items } x 1-x 19\end{array}$} & \multicolumn{2}{|c|}{ Availability (\%) } & \multicolumn{2}{|c|}{ Adequacy (scores \%) } \\
\hline & & Yes & No & Yes & No \\
\hline 1 & Ward for patients & $946(97.5 \%)$ & $274(22.5 \%)$ & $288(23.6 \%)$ & $932(76.4 \%)$ \\
\hline & Medical staff office & $742(60.8 \%)$ & $478(39.2 \%)$ & $220(18.9 \%)$ & $1000(82.0 \%)$ \\
\hline & Conference room & $486(39.8 \%)$ & $734 * *(60.2 \%)$ & $146(12.0 \%)$ & $1074(87.0 \%)$ \\
\hline 4 & Medical library & $282(23.1 \%)$ & $938 * *(76.9 \%)$ & $154(12.6 \%)$ & $1066(87.4 \%)$ \\
\hline & Secretary's office & $912(74.8 \%)$ & $308(25.2 \%)$ & $228(18.7 \%)$ & $992(81.3 \%)$ \\
\hline 6 & Director of nursing's office & $786(60.3 \%)$ & $484(39.7 \%)$ & $190(15.6 \%)$ & $1030(84.4 \%)$ \\
\hline ( & Asst. director of nursing's office & $534(43.8 \%)$ & $686 * *(56.2 \%)$ & $160(13.1 \%)$ & $1060(86.9 \%)$ \\
\hline 8 & Bed and beddings & $868(71.1 \%)$ & $352(28.9 \%)$ & $202(16.6 \%)$ & $1018(83.4 \%)$ \\
\hline 9 & Toilet facilities & $840(68.9 \%)$ & $380(31.1 \%)$ & $206(16.9 \%)$ & $1014(83.1)$ \\
\hline 10 & Water s & $722(59.2 \%)$ & $498(40.8 \%)$ & $182(14.9 \%)$ & $1038(85.1 \%)$ \\
\hline 11 & Water supply & $704(57.7 \%)$ & $516(42.3 \%)$ & $160(13.1 \%)$ & $1060(86.9 \%)$ \\
\hline 12 & Electricity/standby g & $678(55.6 \%)$ & $542(44.4 \%)$ & $138(11.3 \%)$ & $1082(88.7 \%)$ \\
\hline 13 & Telephone Services & $516(42.3 \%)$ & $704 * *(57.7 \%)$ & $82(6.7 \%)$ & $1138(93.3 \%$ \\
\hline 14 & Operation/surgical rooms & $978(80.2 \%)$ & $242(19.8 \%)$ & $184(15.1 \%)$ & $1036(84.9 \%)$ \\
\hline 15 & Consulting rooms & $956(78.4 \%)$ & $264(21.6 \%)$ & $206(16.9 \%)$ & $1014(83.1 \%)$ \\
\hline 16 & tion $(\mathrm{Amb}$ & $768(63.0 \%)$ & $452(37.0 \%)$ & $144(11.8 \%)$ & $1076(88.2 \%)$ \\
\hline 17 & Food vendor or canteen unit & $530(43.4 \%)$ & $690 * *(56.6 \%)$ & $124(10.2 \%)$ & $1096(89.8 \%)$ \\
\hline 18 & Mortuary unit & $548(44.9 \%)$ & $672 *(55.1 \%)$ & $110(9.0 \%)$ & $1110(91.0 \%)$ \\
\hline 19 & Sanitary waste receptacle & $604(49.5 \%)$ & $616 * *(50.3 \%)$ & $110(9.0 \%)$ & $1110(91.0 \%)$ \\
\hline
\end{tabular}

$\mathrm{N}=1220$ frequency and percentage of respondents on availability and adequacy of physical facilities. 
that respondents indicated non-adequacy with very high frequency scores and percentages. This shows that even though the physical facilities were available, they were not adequate. This result confirms the discussion the researcher had with the chief medical officers and director (CMD) and the chief nursing officer (CNO) in some of the health facility visited and the observations made.

The checklist on availability and adequacy of equipment presented in the Table 9, respondent indicated that the equipment were available except ophthalmoscope which had a frequency of $820(67.2 \%)$. But for adequacy of equipment in the same Table, it clearly showed it that virtually all the equipment indicated on the checklist had low frequencies and percentages, indicating that they were inadequate. This findings further justify the claims made by the respective chief medical directors as well as the chief nursing officers respectively.

Findings from the Table 10 on availability and adequacy of diagnostic facilities and equipment show that all were available with the exception of computerized anal with frequency and percentage $1072(87.9 \%)$, ultrasound scanning $1092(89.5 \%)$. Electro Diagnostic facilities 1052 (86.2\%), Electrolyte of urea 718 (58.9\%), Liver function test 930 (76.28) and nutrition/dietician services $786(64.4 \%)$ respectively. On the other hand, it

Table 9: The frequency and percentage of respondents from checklist on availability and adequacy of equipment in effective health care delivery services, in selected state government hospitals in Oyo State, Nigeria $(\mathbf{N}=1220)$

\begin{tabular}{|c|c|c|c|c|c|}
\hline \multirow{2}{*}{$\begin{array}{l}S . \\
\text { No. }\end{array}$} & \multirow[t]{2}{*}{ Items on equipment } & \multicolumn{2}{|c|}{ Availability (Scores and \%) } & \multicolumn{2}{|c|}{ Adequacy (Scores and \%) } \\
\hline & & Yes & $\mathrm{No}$ & Yes & $\mathrm{No}$ \\
\hline 1 & Clinical Laboratory & $916(75.1 \%)$ & $304(24.9 \%)$ & $192(15.7 \%)$ & $1028 * *(84.3 \%)$ \\
\hline 2 & Ophthalmoscopes & $400(32.8 \%)$ & $820 * *(67.2 \%)$ & $70(5.7 \%)$ & $1150 * *(94.3 \%)$ \\
\hline 3 & Sterilizer & $678(55.6 \%)$ & $542(44.4 \%)$ & $110(9.0 \%)$ & $1110 * *(91.0 \%)$ \\
\hline 4 & Autoclave & $752(61.6 \%)$ & $468(38.4 \%)$ & $134(11.0 \%)$ & $1089 * *(89 \%)$ \\
\hline 5 & Dressing cart & $702(57.5 \%)$ & $518(42.5 \%)$ & $146(12.0 \%)$ & $1074 * *(88.0 \%)$ \\
\hline 6 & Stretcher & $818(67.0 \%)$ & $402(33.0 \%)$ & $178(14.6 \%)$ & $1042 * *(85.4 \%)$ \\
\hline 7 & Wheel chair & $740(60.7 \%)$ & $480(39.3 \%)$ & $152(12.5 \%)$ & $1068 * *(87.5 \%)$ \\
\hline
\end{tabular}

Table 10: The frequency and percentage from checklist on availability and adequacy of diagnostic facilities and equipment services in effective health care delivery services $(N=1220)$

\begin{tabular}{|c|c|c|c|c|c|}
\hline \multirow{2}{*}{$\begin{array}{l}\text { S. } \\
\text { No. }\end{array}$} & \multirow{2}{*}{$\begin{array}{c}\text { Tems on diagnostic facilities } \\
\text { and equipment services }\end{array}$} & \multicolumn{2}{|c|}{ Availability (Scores and \%) } & \multicolumn{2}{|c|}{ Adequacy (Scores and \%) } \\
\hline & & Yes & No & Yes & No \\
\hline 1 & X-ray machine & $624(51.1 \%)$ & $596(48.9 \%)$ & $122(10.0 \%$ & $1098(90.0 \%)$ \\
\hline 2 & Computerized anial & $148(12.1 \%)$ & $1072 * *(87.9 \%)$ & $32(2.6 \%)$ & $1188(97.4 \%)$ \\
\hline 3 & Ultrasound & $128(10.5 \%)$ & $1092 * *(89.5 \%)$ & $40(3.3 \%)$ & $1180(96.7 \%)$ \\
\hline 4 & Electro diagnostic facilities & $168(13.8 \%)$ & $1052 * *(86.2 \%)$ & $40(3.3 \%)$ & $1180(96.7 \%)$ \\
\hline 5 & Pathology laboratories & $492(40.3 \%)$ & $728 * *(59.7 \%)$ & $96(7.9 \%)$ & $1124(92.1 \%)$ \\
\hline 6 & Pharmaceutical services & $870(71.3 \%)$ & $350(28.7 \%)$ & $140(11.5 \%)$ & $1080(88.5 \%)$ \\
\hline 7 & Physiotherapy Services & $740(60.7 \%)$ & $480(39.3 \%)$ & $146(12.0 \%)$ & $1074(88.0 \%)$ \\
\hline 8 & Social Services & $532(43.6 \%)$ & $688(56.4 \%)$ & $142(11.6 \%)$ & $1078(88.4 \%)$ \\
\hline 9 & Changing rooms & $676(55.4 \%)$ & $544(44.6 \%)$ & $154(12.6 \%)$ & $1066(87.4 \%)$ \\
\hline 10 & Stock rooms & $776(63.6 \%)$ & $444(36.4 \%)$ & $178(14.6 \%)$ & $1042(85.4 \%)$ \\
\hline 11 & Widal test & $1002(82.1 \%)$ & $218(17.9 \%)$ & $256(21.0 \%)$ & $964(79.0 \%)$ \\
\hline 12 & Pregnancy test & $1048(85.9 \%)$ & $172(14.1 \%)$ & $282(231.1 \%)$ & $938(76.9 \%)$ \\
\hline 13 & Blood group Rh & 1036 & $184(15.1 \%)$ & $268(22.0 \%)$ & $952(78.0 \%)$ \\
\hline 14 & $\mathrm{Hb}$ genotype & $986(80.8 \%)$ & $234(19.2 \%)$ & $246(20.2 \%)$ & $974(79.8 \%)$ \\
\hline 15 & Full blood count & $972(79.7 \%)$ & $248(20.3 \%)$ & $258(21.1 \%)$ & $962(78.9 \%)$ \\
\hline 16 & $\begin{array}{l}\text { Blood transfusion services } \\
\text { blood bank }\end{array}$ & $834(68.4 \%)$ & $386(31.6 \%)$ & $196(16.1 \%)$ & $1024(83.9 \%)$ \\
\hline 17 & Malaria parasite & $1022(83.8 \%)$ & $198(16.2 \%)$ & $282(23.1 \%)$ & $938(76.9 \%)$ \\
\hline 18 & Ante natal screening & $966(79.2 \%)$ & $254(20.8 \%)$ & $254(20.8 \%)$ & $966(79.2 \%)$ \\
\hline 19 & Electrolyte of urea & $502(41.1 \%)$ & $718 * *(58.9 \%)$ & $88(7.2 \%)$ & $1132(94.6 \%)$ \\
\hline 20 & Liver function test & $290(23.8 \%)$ & $930 * *(76.2 \%)$ & $66(5.4 \%)$ & $1154(4.6 \%)$ \\
\hline 21 & Medical examination & $1024(83.9 \%)$ & $196(16.1 \%)$ & $238(19.5 \%)$ & $982(80.5 \%)$ \\
\hline 22 & HIV/AIDS Screening & $732(60.0 \%)$ & $488 \quad(40.0 \%)$ & $226(18.5 \%)$ & $994(81.5 \%)$ \\
\hline 23 & Nutritional dietician services & $434(35.6 \%)$ & $786 * *(64.4 \%)$ & $96(7.9 \%)$ & $1124(92.1 \%)$ \\
\hline
\end{tabular}


was reported from the table that diagnostic facilities and equipment services were not adequate. They all have high frequencies and percentages respectively.

Hence, it shows from the findings that even though the diagnostic facilities and equipment services were available, they were not adequate to ensure effective health care delivery services in selected state government hospitals in Oyo State, Nigeria. The above claim is supported by the findings of Adetunji (2003), on equipment status in Oyo State health care facility who submitted that most equipment were outdated, and needed repairs and many more need to be replaced.

\section{CONCLUSION}

The conclusion drawn from this study shows that facilities is a strong predicting factor in effective health care delivery services as well as provision of equipment which equally significantly predict effective health care delivery services in selected state government hospitals in Oyo state, Nigeria. On the other hand it was found that adequacy of facilities and equipment significantly predict effective health care delivery services while availability of facilities and equipment did not significantly predict effective health care delivery services. In view of the above findings it could be inferred that inadequate or non-availability of facilities, equipment and resources especially basic resources to provide services could be said to have been responsible for substandard care. The lack of basic amenities like water, steam and electricity in our hospitals has hindered the provision of quality health care, proper conduct of tests, therapies, investigations and surgery.

\section{RECOMMENDATIONS}

In view of the outcome of the hypotheses tested for the study and information derived from the checklist of items on availability, adequacy and provision of facilities and equipment for effective health care, to ensure standard health care delivery in our hospitals, it was recommended that the poor state of infrastructure of health facilities and equipment should be addressed through massive renovation of these facilities and replacement of outdated equipments. Also, there should be provision of facilities for some areas under served with secondary health care facilities.

The issue of power generation and constant power supply should be promptly looked into to make these equipment functional. Also broken down equipment should be repaired or replaced promptly as well as setting up an equipment maintenance unit in each health facility that will be properly funded in discharging its functions. There should be adequate motivation and incentives to all categories of staff that are charged with the responsibility of maintaining these facilities and equipment.

Finally, the issue of proper funding should be addressed to keep abreast of other hospitals where the equipment are replaced once new ones appear on the market. Most of the hi-technology equipment are important and in the contemporary world we live in, most of these equipment are changed quite often to make them more sophisticated in order to improve their efficiency and ensure effective health care delivery in our hospitals.

\section{REFERENCES}

Adetunji G 2003. Oyo State Health Care Delivery System 1999-2003. Ibadan, Nigeria: The Lam Adesina Legacy, Book Craft, Ltd.

Awosika BY 1992. Predictors of students' participation in limited resources recreation in the third generation of two Nigerian Universities. Journal of Nigerian Academy of Sports Administration. 1(1\& 2): 51-57.

Best JW, Kahn JV 1986. Research in Education. $5^{\text {th }}$ Edition, Eaglewood Cliffs: A Division of Simon and Schuster Inc.

Encyclopedia Encarta 2000. Hospital. New York: Microsoft Corporation.

Encyclopedia Britannica 2002. Hospital Facilities U.S.A. Encyclopedia Britannica. Inc.

Erinosho L 1996. Managing Human resources, Infrastructure and Equipment in Nigeria, In: OO Kale, OO Dare, BS Fatunbi (Eds.): Better Health in Africa: The Nigerian Perspective. Ibadan: CESTRAD, pp. 6074.

Kerlinger FN, Lee HB 2000. Foundation of Behavioural Research. New York: Hutt, Rinehard and Winston Inc.

Ofi A1998. Direction and Dimension of the 21st Century Nurse in UCH in the New Millennium. Ibadan: Viktor Shegunov Ltd.

Omotosho KA 2002. Medical capabilities Overview. Public Affairs Office, US Embassy. Nigeria. Retrieved December 23, 2003. From http:// www.wadn.org/ healthadminstration in Nigeria. Pdf.

Osuala EC 2000. Introduction to Research Methodology. Ibadan: FEP Publishers Ltd.

Wagnall's Encyclopedia 2002 Types of Hospitals. New York: Funk \& Wagnall Publishing Company. 